anales de psicología, 2018, vol. 34, n 2 (may), 233-240 http://dx.doi.org/10.6018/analesps.34.2.290171
(C) Copyright 2018: Editum. Servicio de Publicaciones de la Universidad de Murcia. Murcia (Spain) ISSN print edition: 0212-9728. ISSN web edition (http://revistas.um.es/analesps): 1695-2294

\title{
Mindfulness and psychotic experiences in college students
}

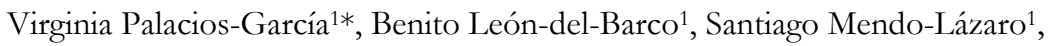 \\ Javier Saavedra-Macías ${ }^{2}$, and Elena Felipe-Castaño ${ }^{1}$ \\ 1 Department of Psychology and Anthropology, University of Extremadura (Spain). \\ 2 Department of Experimental Psychology, University of Sevilla (Spain).
}

\begin{abstract}
Título: Mindfulness y experiencias psicóticas en estudiantes universitarios. Resumen: El estudio de la relación entre experiencias psicóticas y mindfulness en la población general se asocia con la investigación de factores de riesgo y protección frente al desarrollo de un trastorno psicótico. Con este estudio se pretende examinar la presencia de experiencias psicóticas en una muestra de estudiantes universitarios y sus diferencias según el sexo, así como analizar la relación predictiva y discriminante de mindfulness con estas experiencias. Los participantes fueron 526 estudiantes universitarios $(72.8 \%$ mujeres) con una media de edad de 21.39 años $(D T=$ 3.53). Los resultados mostraron la presencia de experiencias psicóticas con diferentes niveles de intensidad, diferencias según el sexo en las mismas, y una relación inversa entre mindfulness y las experiencias psicóticas, y se encontró que las personas con altas puntuaciones en experiencias psicóticas contaron con menores puntuaciones en mindfulness. Estos resultados suponen que mindfulness puede ser un factor de protección en la experimentación de experiencias psicóticas y su entrenamiento puede ser útil para implementación y desarrollo de programas preventivos y de intervención precoz en grupos de riesgo en población general y clínica.
\end{abstract}

Palabras clave: Experiencias psicóticas; mindfulness; alucinaciones; ideación delirante.

\section{Introduction}

Delusional ideations and hallucinations are basic symptoms of psychotic disorders and their presence in people without a clinical diagnosis, known as psychotic experiences, has been described by different authors (Johns and van Os, 2001; Serper, Dill, Chang, Kot and Elliot, 2005). Psychotic experiences are considered qualitatively similar, but quantitatively different, to psychotic symptoms because they are experienced with less frequency, intensity and persistence, and they are associated to lower levels of disability (Serper et al., 2005; Verdoux \& van Os, 2002). However, when the frequency \& intensity of these experiences increases (Domínguez, Wichers, Lieb, Wittchen \& van Os, 2011; Smeets et al., 2012), and there is exposure to environmental risk factors (Cougnard et al. 2007), the probability of suffering a psychotic disorder rises.

The studies reviewed in the adult population outline percentages of suffering psychotic experiences ranging from $5 \%$ (Mojtabai, 2006; Wiles et al., 2006; van Os, Linscott, MyinGermeys, Delespaul, Krabbendam, 2009), a figure which is repeated in the analysis of adolescent and child populations (Scott et al., 2009), up to 35\% (Loewy, Johnson \& Cannon, 2007). In a sample of 777 young people (Obiols, Barragán, Vicens \& Navarro, 2008), 44.1\% declared that they had experienced at least one psychotic symptom.

* Correspondence address [Dirección para correspondencia]:

Virginia Palacios-García. Facultad de Formación del Profesorado. Universidad de Extremadura. Avd.de la Universidad s/n C.P. 10003 Cáceres (Spain). E-mail: virginiapg@gmail.com
Abstract: The study of the relation between psychotic experiences and mindfulness in the general population is linked to research into factors of risk and protection against the development of a psychotic disorder. This study looks into the presence of psychotic experiences in a sample of university students and whether there is any variation according to gender. It also analyzes the predictive and discriminant relation of mindfulness with these experiences. The sample consisted of 526 university students $(72.8 \%$ women) with a mean age of 21.39 years $(S D=3.53)$. The results showed the presence of psychotic experiences with differing levels of intensity, with variations according to gender, and an inverse relationship between mindfulness and psychotic experiences. Results indicated that students with high scores in psychotic experiences had lower scores in mindfulness. Our findings imply that mindfulness may be a factor of protection against psychotic experiences and its training may have a role to play in the development and implementation of preventive and early intervention programs in risk groups in the general and clinical population.

Keywords: Psychotic experiences; mindfulness; hallucinations; delusional ideation.

The presence of psychotic experiences in the general population has been related to variables such as gender and age. There is no agreement among researchers over differences according to gender. Kwapil, Barrantes, Vidal and Silvia (2008) found a greater frequency of hallucinatory experiences in women; however, other studies have not confirmed this difference, either in adult (Miettunen \& Jääskeläinen, 2010) or adolescent populations (Fonseca-Pedrero et al., 2009; Scott et al., 2009). As for age, an inverse relation has been found with delusional ideation (Calkins et al., 2014; Scott, Chant, Andrews \& McGrath, 2006) both in the general and clinical population (Verdoux \& van Os, 2002). It is generally considered that psychotic experiences present with greater frequency in childhood and adolescence (Altman, Collins \& Mundy, 1997; Calkins et al., 2014; Laroi, Van der Linden \& Goëb, 2006). Furthermore, early adulthood appears to be a critical life moment for the expression of the features of psychosis (Verdoux et al., 1998).

Mindfulness is defined as a type of attention directed at present experience (Baer, 2010; Brown \& Ryan, 2003). It is not a unitary concept, instead it has three interdependent components: the self-regulation of internal attentional processes, attention to the present moment, and the direction of the attentional focus towards day-to-day activities (Bishop, Duncan \& Lawrence, 2004; Brown \& Ryan, 2003); openness to experience and acceptance, nonjudgment of feelings, thoughts and events of daily life; and finally, letting go (Baer, Smith \& Allen, 2004).

In recent years there has been a growth in research interest into the influence of mindfulness training on attention. In a sample of university students who received mindfulness 
training, Barragán, Lewis and Palacio (2007) found an improvement in their ability to maintain and focus attention, cope with distractions and follow a stimulus attentively. Mindfulness practices are being incorporated into the theory and practice of psychotherapy, health psychology and neurosciences. They are seen as having significant repercussions for different areas of people's lives (Langer, 2007), such as a reduction in physical and psychological symptoms, or improvement in general health (Grossman, Niemann, Schmidt \& Walach, 2004; Hofmann, Sawyer, Witt, Oh, 2010) in addition to favoring the functioning of different brain regions and morphological changes in the brain cortex (Simón, 2007). Mindfulness has been studied in people with psychotic disorders and dissociative experiences with a negative association being found with the experiencing of hallucinations, the anxiety associated to the experience and the characteristics of voices such as their resistance or evil (Chadwick, Barnbrook \& Newman-Taylor, 2007) and with depersonalization and absorption (Perona-Garcelán, GarcíaMontes, López-Jiménez \& Rodríguez-Testal, 2014).

Research interest into the relation between psychotic experiences and mindfulness in the general population focuses on factors of risk and protection against the development of psychotic symptoms. The general population does not present the associated difficulties that appear in the clinical population, such as the consumption of medication, and the studies that analyzing the influence of mindfulness on psychotic experiences among the general population could prepare the ground for prevention and intervention strategies for risk groups and first psychotic episodes.

This study looks into the presence of psychotic experiences (delusional ideation and hallucinations) in university students by gender and age, and analyzes the predictive and discriminant relation between mindfulness and the presence of psychotic experiences. As principal hypothesis of our investigation, we proposed that mindfulness will be a predictor of the frequency of psychotic experiences, in the sense that greater mindfulness would predict a lower frequency of psychotic experiences.

\section{Method}

\section{Participants}

Participants were selected using cluster probability sampling of university degrees at the Universidad de Extremadura, with a random selection of degrees and courses. The sample was incidental and consisted of 526 students without a history of psychopathological disorders; 383 were women $(72.8 \%)$. Their mean age was 21.39 years $(S D=3.53)$ with ages ranging from 18 to 48 .

\section{Instruments}

Sociodemographic data referring to age, gender, level of studies and psychopathological history.
The 21-item Peters et al. Delusions Inventory (PDI-21; Peters, Joseph, Day \& Garety, 2004). Spanish adaptation by LópezIlundain, Pérez-Nievas, Otero and Mata (2006). A 21 item self-report tool designed to assess delusional ideation in the general population, with a yes/no answer format. A global score is obtained with seven dimensions: Experiences of influence, Depressive, Paranoid, Grandiosity, Referential, Magic thinking and Religiousness. Furthermore, in each of the items the level of distress, preoccupation and conviction is assessed, following a five-interval Likert type response format. Cronbach Alpha values can be seen in Table 1 .

Launay-Slade Hallucination Scale-Revised (LSHS-R; Bentall \& Slade, 1985). Spanish adaptation by Fonseca-Pedrero et al. (2010). A self-report assessing hallucinatory predisoposition in clinical and general populations. It has 12 Likert-type response items with four response intervals from 1 "certainly does not apply to you" to 4 "certainly does apply to you". It has two scales: Vivid Mental Events, related to dreamlike and cognitive components of hallucinations and Hallucinatory Experiences, hearing voices or seeing objects and people that are not present a more perceptive component. The internal consistency value obtained using Cronbach's alpha can be seen in Table 1.

Mindful Attention Awareness Scale (MAAS; Brown \& Ryan, 2003). Spanish adaptation by Soler et al. (2012). A scale for the overall assessment of the dispositional capacity of a person to be attentive and conscious of the experience of the current moment in daily life. It features 15 items with a Likert-type response format with six intervals ranging from 1 "nearly always" to 6 "hardly ever". Higher scores indicate a greater state of mindfulness. An internal consistency value was obtained using Cronbach's alpha and can be seen in Table 1.

\section{Procedure}

The questionnaires were collected in groups of 20 to 25 students. Once the groups of students have been selected, they are contacted by going directly to the classroom, during practical classes when the number of students was lower They were asked to take part voluntarily and gave their written consent, with the guarantee that the data collected would be kept confidential and anonymous and would only be used for research purposes. The questionnaires took roughly forty minutes to complete with the research team present throughout.

\section{Data analysis}

The analysis was conducted using version 21.0 of the SPSS statistical analysis software package for PC, with a confidence interval of $95 \%$. The statistics used were: descriptive analyses, Kolmogorov-Smirnov normality test, linear correlation analysis, Student's- $t$ test for independent samples, Cohen's $d$ for the calculation of effect size, linear regression analysis and discriminant analysis. 


\section{Results}

\section{Response frequency}

The highest scores of the PDI-21 were obtained in the dimensions Grandiosity and Magic thinking, and the lowest scores in the Paranoid and Religiousness dimensions. In the LSHS-R, the highest score was obtained in Vivid Mental Events (see Table 1).

In PDI-21, 98.7\% of the participants responded affirmatively to at least one of the items, and .2\% responded affirm- atively to all items. A score of 7 or higher was obtained by $44.29 \%, M d n=6$. While $1.7 \%$ of the participants responded that they had never experienced any of the situations described in the LSHS-R, $74.52 \%$ answered "frequently" or "nearly always" to at least one item. There were 77 subjects $(14.63 \%)$ with a greater propensity towards hallucinations, with scores above the standard deviation for the mean, of these $77.93 \%$ were women. In contrast, there were 53 subjects $(10.07 \%)$ with less propensity towards hallucinations, those scoring below the standard deviation for the mean, of these $66.04 \%$ were women.

$\underline{\text { Table 1. Descriptive statistics and Cronbach's Alpha }(\alpha) \text { of the PDI-21, LSHS-R and MAAS. }}$

\begin{tabular}{|c|c|c|c|c|c|c|c|c|}
\hline & & \multirow{2}{*}{$M$} & \multirow{2}{*}{$S D$} & \multirow{2}{*}{ Min } & \multirow{2}{*}{$\operatorname{Max}$} & Asymmetry & \multicolumn{2}{|l|}{ Kurtosis } \\
\hline & & & & & & St & St & $a$ \\
\hline \multirow{8}{*}{ PDI-21 } & Experiences of influence & 1.00 & 1.01 & 0 & 3 & .63 & -.76 & .53 \\
\hline & Depressive & .86 & .96 & 0 & 4 & 1.05 & .49 & .42 \\
\hline & Paranoid & .39 & .61 & 0 & 2 & 1.34 & .68 & .39 \\
\hline & Referential & 1.49 & .84 & 0 & 3 & -.19 & -.61 & .35 \\
\hline & Grandiosity & 6.12 & .75 & 0 & 2 & .77 & -.83 & .50 \\
\hline & Magic thinking & 1.82 & .95 & 0 & 4 & .51 & -.37 & .38 \\
\hline & Religiousness & .23 & .56 & 0 & 2 & 2.33 & 4.14 & .71 \\
\hline & PDI-21 Total & 6.40 & 3.45 & 0 & 20 & .66 & .27 & .76 \\
\hline \multirow{3}{*}{ LSHS-R } & Vivid Mental Events & 11.07 & 2.92 & 6 & 24 & .74 & .77 & .65 \\
\hline & Hallucinatory Experiences & 8.20 & 1.90 & 6 & 24 & 2.33 & 12.59 & .61 \\
\hline & LSHS-R Total & 19.27 & 4.29 & 12 & 48 & 1.25 & 4.23 & .77 \\
\hline MAAS & Total & 72.70 & 10.41 & 26 & 90 & -.66 & .63 & .89 \\
\hline
\end{tabular}

Note: PDI-21 Total= Overall score in The 21-item Peters et al. Delusions Inventory; LSHS-R Total = Overall score in the Launay-Slade Hallucination ScaleRevised.

\section{Differences according to gender in psychotic expe-} riences

Using the Kolmogorov-Smirnov test we verified that the distribution was normal in all dimensions of the PDI-21 and the
LSHS-R. Table 2 shows the descriptive statistics of the scores of the dimensions of the different scales according to gender.

Table 2. Overall score and Dimensions of PDI-21, LSHS-R and MAAS. Comparison of means according to gender and effect size (Cohen's d).

\begin{tabular}{|c|c|c|c|c|c|c|c|c|}
\hline & \multirow[b]{2}{*}{ Dimensions } & \multicolumn{2}{|c|}{$\begin{array}{c}\text { Men } \\
(\mathrm{n}=143)\end{array}$} & \multicolumn{2}{|c|}{$\begin{array}{l}\text { Women } \\
(\mathrm{n}=383)\end{array}$} & \multirow[b]{2}{*}{$t$} & \multirow[b]{2}{*}{$p$} & \multirow[b]{2}{*}{$d$} \\
\hline & & $M$ & $S D$ & $M$ & $S D$ & & & \\
\hline \multirow{8}{*}{ PDI-21 } & Experiences of influence & .98 & .99 & 1.01 & 1.04 & -1.29 & .898 & -.02 \\
\hline & Depressive & .81 & .91 & .87 & .98 & -.695 & .488 & -.06 \\
\hline & Paranoid & .35 & .64 & .40 & .61 & -.887 & .376 & -.07 \\
\hline & Referential & 1.40 & .89 & 1.52 & .82 & -1.43 & .153 & .14 \\
\hline & Grandiosity & .81 & .83 & .48 & .69 & 4.89 & $<.001$ & .43 \\
\hline & Magic thinking & 1.60 & .95 & 1.90 & .93 & -3.15 & .002 & -.31 \\
\hline & Religiousness & .20 & .50 & .25 & .58 & -.959 & .339 & -.09 \\
\hline & PDI-21 Total & 6.17 & 3.34 & 6.48 & 3.49 & -.922 & .358 & -.09 \\
\hline \multirow{3}{*}{ LSHS-R } & Vivid Mental Events & 10.85 & 2.92 & 11.15 & 2.92 & -1.04 & .299 & -.10 \\
\hline & Hallucinatory Experiences & 8.48 & 2.42 & 8.10 & 1.66 & 1.70 & .045 & .18 \\
\hline & LSHS-R Total & 19.33 & 4.81 & 19.25 & 4.09 & .166 & .868 & .001 \\
\hline$\overline{\text { MAAS }}$ & Total & 72.68 & 9.86 & 72.71 & 10.61 & -.032 & .974 & -.002 \\
\hline
\end{tabular}

Note: PDI-21 Total= Overall score in The 21-item Peters et al. Delusions Inventory; LSHS-R Total = Overall score in the Hallucination Scale-Revised by Launay-Slade; $d=$ Cohen's d.

We did not find differences according to gender in the total scores of the questionnaires, but we did find statistically significant differences according to gender in the Magic
Thinking dimension in the sense that women obtained higher scores than men, while men obtained higher scores in Grandiosity and Hallucinatory Experiences. According to 
these results, women have a greater belief in hidden forces and their hallucinatory experiences are more cognitive than perceptive; men, in contrast, have the feeling that they are important or out of the ordinary, showing a greater frequency of experiences related to the perceptive component of hallucinations.

\section{Relation between age and psychotic experiences.}

We found statistically significant and inverse correlations, albeit with low relational strength, between age and the overall score of the PDI-21, $r=-.141, p<.001$, and the dimensions Experiences of Influence, $r=-.155, p<.001$, Depressive, $r=-.104, p=.017$, and Referential, $r=-.130, p<.003$. Likewise, we found statistically significant inverse correlations between age and the LSHS-R scales: Hallucinatory Experiences, $r=-.1 .46, p<.001$, and Vivid Mental Events, $r=$ $.183, p<.001$, as well as with their overall score, $r=-.189$, $p$ $<.001$.

\section{Predictive and discriminant relation between Mind- fulness and Psychotic Experiences}

First of all, we calculated the correlation coefficients and found inverse and statistically significant correlations between MAAS scores and the overall scores of the PDI-21, $r$ $=-.470, p<.001$, and the LSHS-R, $r=-.525, p<.001$. The dimensions of the PDI-21 correlated with MAAS from the Religiousness, $r=-.137, p<.001$, to the Depressive dimen- sions, $r=-.365, p<.001$. In turn, the Hallucinatory Experiences, $r=-.342, p<.001$, and Vivid Mental Events dimensions, $r=-.549, p<.001$, of the LSHS-R correlated significantly with the overall MAAS score.

To determine the extent to which mindfulness is related to pscyhotic experiences, we conducted several single model linear regression analyses, in which the dependent variables were the overall scores in PDI-21 and LSHS-R, and the independent variable was the overall MAAS score. We performed the regression analyses with the complete sample, segmented by gender. To do so, we analyzed the premises of the linear regression model, verifying firstly that there were no problems of multicollinearity (FIV below 10 and Tolerance over 0.1). We then checked for normal distribution using the Kolmogorov-Smirnov test, and that there was a linear relation between predictors and dependent variables, confirmed through the analysis of the scatterplot.

These analyses revealed, that the predictive model of delusional ideation and mindfulness in the total sample explained $22 \%$ of the variance, $F(1,524)=148.671, p<.001$, $19.4 \%$ of the variance in men, $F(1,141)=33.906, p<.001$, and $23.1 \%$ of the variance in women, $F(1,381)=114.419, p$ $<.001$, being significant in all the samples. In turn, the predictive model of hallucinations and mindfulness in the overall sample explained $27.6 \%$ of overall variance, $F(1,524)=$ $199.447, p<.001,24.6 \%$ of the variance in men, $F(1,141)=$ 46.106, $p<.001$, and $29.3 \%$ of the variance in women, $F(1$, $381)=157.578, p<.001$. It was also significant in all the samples (see Table 3).

Table 3. Partial regression coefficients. VD Psychotic Experiences.

\begin{tabular}{|c|c|c|c|c|c|c|c|}
\hline \multirow{2}{*}{$\begin{array}{l}\text { Psychotic } \\
\text { Experiences }\end{array}$} & \multirow{2}{*}{$\begin{array}{c}\text { Mindfulness predictor } \\
\text { variables }\end{array}$} & \multicolumn{2}{|c|}{ Non standardized coefficients } & \multirow{2}{*}{$\frac{\text { Standardized coefficients }}{\text { Beta }}$} & \multirow[b]{2}{*}{$t$} & \multirow[b]{2}{*}{$p$} & \multirow[b]{2}{*}{ Durbin-Watson } \\
\hline & & $\mathrm{B}$ & Standard Error & & & & \\
\hline \multirow{3}{*}{ PDI-21 } & MAAS Total & -.156 & .013 & -.470 & -12.193 & $<.001$ & 1.737 \\
\hline & MAAS Men & -1.301 & .223 & -.440 & -5.823 & $<.001$ & 1.670 \\
\hline & MAAS Women & -1.460 & .136 & -.481 & -10.697 & $<.001$ & 1.841 \\
\hline \multirow{3}{*}{ LSHS-R } & MAAS Total & -.217 & .015 & -.525 & -14.125 & $<.001$ & 1.676 \\
\hline & MAAS Men & 1.018 & .150 & -.496 & -6.790 & $<.001$ & 1.726 \\
\hline & MAAS Women & -1.403 & .112 & -.541 & -12.553 & $<.001$ & 1.721 \\
\hline
\end{tabular}

To analyze the capacity of the MAAS score to discriminate between the different levels of psychotic experiences, we formed four groups of participants according to the frequency with which they had had such experiences. Group I included subjects with low scores $(\leq P 33, M=79.52, S D=$ 7.32), in both the PDI-21 and the LSHS-R; Group II consisted of subjects with high scores ( $>$ P66, $M=69.09$, SD = 9.09), in the LSHS-R; Group III included subjects with high scores $(>P 66, M=72.26, S D=8.80)$ in the PDI-21; and finally, Group IV was made up of participants with high scores $(>P 66, M=63.08, S D=11.01)$, in both questionnaires.

We checked the supposition of linearity, normality and equality of the variances-covariances of the variables involved. We found significant differences in mindfulness between the four groups using a variance analysis ( $A N O V A$ ),
(Wilks $\lambda=.684, F=53.322, p<.001, \eta=.316$ ), except between Group II and Group III.

The discriminant function showed an adequate canonical correlation and distance between groups (Wilks $\lambda$ closer to $0)$. Furthermore, the Chi squared analysis presented an adequate level of significance. The function presented a canonical correlation of $.562, \rho(3)=131.681, p<.001$.

The means and sign of the functions allow us to conclude that Group I had the greatest predictive capacity, .908), followed by Group IV, -.897, Group II, -.237, and finally Group III, .111. In short, Group I (low in psychotic experiences) discriminated from the rest by having a higher score in mindfulness, while Group IV (high in psychotic experiences) obtained the lowest score in mindfulness. Groups II (high in hallucinations) and III (high in delusional ideation) did not have that discriminative capacity. 
The confusion matrix provides the results of the classification (see Table 4). It shows that $44.9 \%$ of the subjects were classified correctly, a figure which exceeds the $33 \%$ expected in a completely random classification in the four categories of psychotic experiences. The discriminant canonical func- tion obtained permitted the correct classification of $73.3 \%$ of the subjects in the group with low psychotic experience (Group I) and $60.2 \%$ of the subjects in the group with high psychotic experience (Group IV).

Table 4. Results of the classification using the discriminant function.

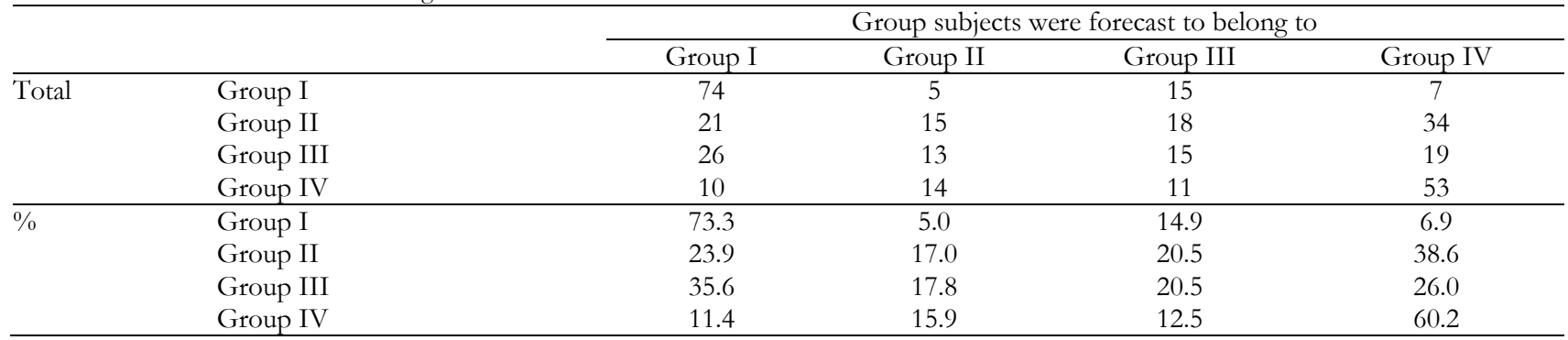

Classified correctly: $44.9 \%$ of the originally grouped cases

Note: Group I = Low psychotic experience; Group II = High hallucination; Group III = High delusional ideation; Group IV = High psychotic experience.

\section{Discussion and conclusions}

The purpose of this study was to examine the presence of psychotic experiences (hallucinations and delusional ideation) in university students and analyze the predictive and discriminant relation between mindfulness and the frequency of psychotic experiences.

Participants informed of the presence of psychotic experiences reinforcing the dimensional view of these experiences in the general population (Rössler et al., 2007). Dimensional models provide a more accurate representation of the variation in mental health among the general population because they do not solely explore the presence or absence of a specific symptom (Hanssen et al., 2003). The proportion of participants who answered affirmatively to seven or more items of the PDI-21was higher in this study than in that of Fonseca-Pedrero, Paino, Santarén-Rosell and Lemos Giráldez (2012) which was also conducted with university students. Other studies, such as that by So and Kwok (2015), found higher overall scores in non-clinical participants in the PDI21 than those obtained in our study.

As for the propensity towards hallucinations, the mean score obtained was slightly higher to that obtained in other studies performed with the same type of population (Fonseca-Pedrero et al., 2010; Jaén 2014; Serper et al., 2005). Despite the presence of psychotic experiences in the participants, none of them said they had a psychopathological diagnosis. There must therefore be factors which precipitate or protect against the appearance of a psychotic disorder. Thus, hallucinations may be conceived as such, as a complex experience with multiple cognitive processes related to memory or thought, and not just as a perceptive experience (PeronaGarcelán et al., 2008).

The divergence in the above-mentioned data highlights two points. On the one hand, it underlines how difficult it is to establish a cut-off point beyond which one may be considered to have a greater propensity towards delusional idea- tion. On the other, it reveals the great diversity in the contents of delusional ideation in the general population, confirming the dimensional view of the psychosis phenotype (Kelleher \& Cannon, 2011).

There were no differences according to gender in the overall scores of the questionnaires, but some did appear in the scales. Women obtained higher scores in the Magic Thinking dimension of the PDI-21 and in the Vivid Mental Events of the LSHS-R. In contrast, men scored higher in the Grandiosity dimension, which is similar to results in other studies (López-Illundain et al. 2006; Scott et al., 2008), and in the Hallucinatory Experiences scale, which coincides with data obtained by Kwapil et al., (2008).

These differences may be explained by differences in the cognitive functions of men and women: men perform worse in attention, verbal capacity and executive functions (Hoff et al., 1998), and they undergo a greater number of cerebral morphological alterations (Andreasen, Flaum, Swayze, Tyrrell \& Arndt, 1990). Women, in contrast, have greater difficulties in visual processing (Lewine, Walker, Shurett, Caudle \& Haden, 1996), which could explain why they score lower in aspects related to the perceptive components of psychotic experiences and have a higher frequency of affective symptoms and paranoid forms (Cotton et al, 2009). In this study, women's mean scores in the Paranoid dimension were higher than men's, although these differences were not statistically significant.

The results confirm the inverse relation between age and psychotic experiences along the lines of the work by Calkins et al. (2014) and Scott et al., (2006).

Our second objective was to analyze the predictive and discriminant capacity of mindfulness on the presence of psychotic experiences. We found an inverse correlation between psychotic experiences and mindfulness, a result which coincides with Chadwick et al., (2007) and Perona-Garcelán et al. $(2013,2014)$. The score in mindfulness managed to discriminate between the different groups of psychotic experiences: 
the group with high scores in delusional ideation and hallucinations obtained lower scores in mindfulness. People with low scores in mindfulness tend to have difficulties with their selective attention and take longer to perform specific tasks (Lapcin et al., 2008). Attentional biases could play an important role, both in the development and maintenance of delusional ideation and hallucinatory experiences, because these people tend to process the stimuli more quickly because of their threatening nature (Gilleen \& David, 2005), and this interferes with their ability to pay attention to the present moment in an intentional and judgment-free way, a basic conception in mindfulness (Kabat-Zinn, 1994).

In the same way, people with greater attentional capacity for the present moment report fewer psychotic experiences. This may be due to the fact that these subjects have greater cognitive resources related to attention such as memory, ability to concentrate, and reasoning, amongst others. These resources may make it easier for them to discriminate between real or unreal experiences in the event of given cognitive errors which are present in psychotic experiences, such as the ability to select the most important information in a given situation or the interpretation of certain facts when they are considered dangerous (Gilleen \& David, 2005).

Future research should attempt to clarify the concept of mindfulness and how it relates to other psychopathological symptoms, and its influence on certain basic psychological processes such as cognitive insight, memory and perception. The results presented in this study should be taken with a certain degree of caution due to the study because was crosssectional design, and homogeneity of the sample in terms of variables such as socio-educational level and age, which may

\section{References}

Altman, H., Collins, M., \& Mundy, P. (1997). Subclinical hallucinations and delusions in nonpsychotic adolescents. Journal of Child Psychology and Psychiatry, 38(4), 413-420. doi: 10.1111/j.1469-7610.1997.tb01526.x

Andreasen, N. C., Flaum, M., Swayze, V. W., Tyrrell, G., \& Arndt, S. (1990). Positive and negative symptoms in schizophrenia. A clinical reappraisal. Archives of General Psychiatry, 47(7), 615-621.

Baer, R. A. (2010). Assessing mindfulness and acceptance processes in clients: Illuminating the theory and practice of change. New York: New Harbinger Publications.

Baer, R. A., Smith, G. T., \& Allen, K. B. (2004). Assessment of mindfulness by self-report the Kentucky inventory of mindfulness skills. Assessment, 11(3), 191-206. doi: 10.1177/1073191104268029

Barragán, R., Lewis, S., \& Palacio, J. E. (2007). Auto-perception of the changes in the intermediary attention deficits of university students in Barranquilla submitted to the attention self-control Mindfulness method. Revista Salud Uninorte, 23(2), 184-192.

Bentall, R. P., \& Slade, P. D. (1985). Reliability of a scale measuring disposition towards hallucination: a brief report. Personality and Individual Differences, 6(4), 527-529. doi: 10.1016/0191-8869(85)90151-5

Bishop, S. J, Lau, M., Shapiro, S., Carlson, L., Anderson, N., Carmody, J., \& Segal, Z. (2004). Mindfulness: A Proposed Operational Definition. Clinical Psychology- Science and Practice, 11, 230-241. doi:10.1093/clipsy.bph077

Brown, K. W., \& Ryan, R. M. (2003). The benefits of being present: mindfulness and its role in psychological well-being. Journal of Personality and Social Psychology, 84(4), 822-848. doi: 10.1037/0022-3514.84.4.822 make it more difficult to extrapolate the results to other population groups. The use of self-reports should be complemented by other instruments for collecting information, such as interviews, which would allow a more precise characterization of the phenomenological quality of the psychotic experience (Stanghellini, Langer \& Cangas, 2012). This could also help overcome difficulties arising over the comprehension of certain items in the questionnaires which may have seemed implausible or difficult to understand for the person being assessed.

Despite its limitations, this study highlights the presence of psychotic experiences in our participants, providing evidence that the study of these experiences is better approached from a comprehensive dimensional model of the phenomenon. We found a predictive and discriminant association between mindfulness and psychotic experiences. The discriminative capacity of mindfulness on different levels of psychotic experiences provides another explanatory element. It would also seem to support the idea of developing new intervention approaches based on mindfulness training because they have proved their effectiveness in depressive symptomatology, where the exposure of people to contents of their own consciousness helps them to experience their emotions with less reactivity and greater objectivity (Segal, Williams \& Teasdale, 2002). Furthermore, practicing mindfulness generates changes in attitudes and patterns of thinking, facilitating greater self-control and more adaptive responses towards certain psychological and physical components (Delgado, 2009). This is an aspect which may be crucial for both prevention and intervention in people with psychotic symptoms or disorders.

Calkins, M. E., Moore, T. M., Merikangas, K. R., et al. (2014). The psychosis spectrum in a young US community sample: findings from Philadelphia Neurodevelopmental Cohort. World Psychiatry, 13(3), 296-305. doi: 10.1002/wps.20152

Chadwick, P. D. J., Barnbrook, E., \& Newman-Taylor, K. (2007). Responding mindfully to distressing voices: links with meaning, affect and relationship with voice. Journal of the Norwegian Psychological Association, 44, 581-588.

Cotton, S. M., Lambert, M., Schimmelmann, B. G., Foley, D. L., Morley, K. I., McGorry, P. D., \& Conus, P. (2009). Gender differences in premorbid, entry, treatment, and outcome characteristics in a treated epidemiological sample of 661 patients with first episode psychosis. Schizophrenia Research, 114(1), 17-24. doi: 10.1016/j.schres.2009.07.002

Cougnard, A., Marcelis, M., Myin-Germeys, I., De Graaf, R., Vollebergh, W., Krabbendam, L., \& Van Os, J. (2007). Does normal developmental expression of psychosis combine with environmental risk to cause persistence of psychosis? A psychosis proneness-persistence model. Psychological Medicine, 37(4), 513-528. doi: 10.1017/S0033291706009731

Delgado, L. C. (2009). Correlatos psicofisiológicos de mindfulness y la preocupación. Eficacia de un entrenamiento en habilidades Mindfulness [Psychophysiological correlates of mindfulness and worry. Effectiveness of skills training in Mindfulness]. Granada: Editorial de la Universidad de Granada.

Domínguez, M. D. G., Wichers, M., Lieb, R., Wittchen, H. U., \& van Os, J. (2011). Evidence that onset of clinical psychosis is an outcome of progressively more persistent subclinical psychotic experiences: an 8-year cohort study. Schizophrenia Bulletin, 37(1), 84-93. doi: $10.1093 / \mathrm{schbul} / \mathrm{sbp} 022$ 
Fonseca-Pedrero, E., Lemos-Giráldez, S., Paino, M., Sierra-Baigrie, S., Villazón-García, U., García-Portilla, M., \& Muñiz, J. (2010). Dimensionality of hallucinatory predisposition: Confirmatory factor analysis of the Launay-Slade Hallucination Scale-revised in college students. Anales de Psicología 26(1), 41-48.

Fonseca-Pedrero, E., Lemos-Giráldez, S., Paino, M., Sierra-Baigrie, S., Villazón-García, U., \& Muñiz, J. (2009). Experiencias psicóticas atenuadas en población adolescente [Attenuated psychotic experiences in adolescents]. Papeles del Psicólogo, 30(1), 63-73.

Fonseca-Pedrero, E., Paino, M., Santarén-Rosell, M., Lemos-Giráldez, S., \& Muñiz, J. (2012). Psychometric properties of the Peters et al Delusions Inventory 21 in college students. Comprehensive Psychiatry, 53(6), 893-899. doi: 10.1016/j.comppsych.2012.01.007

Gilleen, J., \& David, A. S. (2005). The cognitive neuropsychiatry of delusions: from psychopathology to neuropsychology and back again. Psychological Medicine, 35(1), 5-12. doi: 10.1017/S0033291704003976

Grossman, P., Niemann, L., Schmidt, S., \& Walach, H. (2004). Mindfulness-based stress reduction and health benefits: A meta-analysis. Journal of Psychosomatic Research, 57(1), 35-43. doi; 10.1016/S00223999(03)00573-7

Hanssen M, Peters F, Krabbendam L, Radstake, S., Verdoux, H. \& van Os, J. (2003). How psychotic are individuals with non-psychotic disorders? Social Psychiatry and Psychiatric Epidemiology, 38, 149-54. doi: 10.1007/s00127-003-0622-7

Hofmann, S. G., Sawyer, A. T., Witt, A. A., \& Oh, D. (2010). The effect of mindfulness-based therapy on anxiety and depression: A meta-analytic review. Journal of Consulting and Clinical Psychology, 78(2), 169-183. doi: $10.1037 / \mathrm{a} 0018555$

Hoff, A. L., Wieneke, M., Faustman, W. O., Horon, R., Sakuma, M., Blankfeld, H., \& DeLisi, L. E. (1998). Sex differences in neuropsychological functioning of first-episode and chronically ill schizophrenic patients. American Journal of Psychiatry, 155,1437-1439.

Jaén-Moreno, M. J., Moreno-Díaz, M. J., Luque-Luque, R., \& Bell, V. (2014). Validation of the Spanish version of the Cardiff Anomalous Perceptions Scale in the general population. Actas Españolas de Psiquiatría, 42(1), 1-8.

Johns, L. C., \& van Os, J. (2001). The continuity of psychotic experiences in the general population. Clinical Psychology Review, 21(8), 1125-1141. doi: 10.1016/S0272-7358(01)00103-9

Kabat-Zinn, J. (1994). Wherever you go, there you are: Mindfulness meditation in everyday life. New York: Hyperion.

Kelleher, I., \& Cannon, M. (2011). Psychotic-like experiences in the general population: characterizing a high-risk group for psychosis. Psychological Medicine, 41(1), 1-6. doi: 10.1017/S0033291710001005

Kwapil, T. R., Barrantes-Vidal, N., \& Silvia, P. J. (2008). The dimensional structure of the Wisconsin schizotypy scales: Factor identification and construct validity. Schizophrenia Bulletin, 34(3), 444-457. doi: $10.1093 / \mathrm{schbul} / \mathrm{sbm} 098$

Langer, E. J. (2007). Mindfulness. Conciencia Plena [Mindfulness]. Barcelona: Paidós.

Lapcin, S., Guler, J., Ceylan, E., Maner, F., Ger, C., \& Satmis, N. (2008). Attention impairment in patients with paranoid schizophrenia and delusional disorder: A controlled study. International Journal of Neuropsychopharmacology, 11(2), 251-260.

Laroi, F., Van der Linden, M., \& Goëb, J. L. (2006). Hallucinations and delusions in children and adolescents. Current Psychiatry Reviews, 2(4), 473485. doi: $10.2174 / 157340006778699756$

Lewine, R. R. J., Walker, E. F., Shurett, R., \& Caudle, J., \& Haden, C. (1996). Sex differences in neuropsychological functioning among schizophrenic patients. The American Journal Psychiatry, 153(9), 11781184.

Loewy, R. L., Johnson, J. K., \& Cannon, T. D. (2007). Self-report of attenuated psychotic experiences in a college population. Schizophrenia Research, 93(1), 144-151. doi: http://dx.doi.org/10.1016/j.schres.2007.02.010

López-Ilundain, J. M., Pérez-Nievas, F., Otero, M., \& Mata, I. (2006). El Inventario de experiencias delirantes de Peters (PDI) en población general española: fiabilidad interna, estructura factorial y asociación con variables demográficas [The Delusions Inventory of Peters (PDI) in spanish general population: reliability, structure factorial and association with demographic variables]. Actas Españolas de Psiquiatría, 34(2), 94-104.

Miettunen, J., \& Jääskeläinen, E. (2010). Sex differences in Wisconsin Schizotypy Scales: A meta-analysis. Schizophrenia Bulletin, 36(2), 347-358. doi:10.1093/schbul/sbn075

Mojtabai, R. (2006). Psychotic-like experiences and interpersonal violence in the general population. Social Psychiatry and Psychiatric Epidemiology, 41(3), 183-190. doi:10.1007/s00127-005-0020-4

Obiols, J. E., Barragán, M., Vicens, J., \& Navarro, J. B. (2008). Síntomas seudo-psicóticos en adolescentes de la población general. [Pseudopsychotic symptoms in adolescents from the general population]. Revista de Psicopatología y Psicología Clínica, 13(3), 205-217. doi: 10.5944/rppc.vol.13.num.3.2008.4060

Perona-Garcelán, S., Cuevas-Yust, C., García-Montes, J. M., et al. (2008). Relationship between self-focused attention and dissociation in patients with and without auditory hallucinations. Journal of Nervous and Mental Disease, 196(3), 190-197. doi: 10.1097/NMD.0b013e318165c7c1

Perona-Garcelán, S., García-Montes, J. M., López-Jiménez, A. M., Rodríguez-Testal, J. F., et al. (2014). Relationship between SelfFocused Attention and Mindfulness in People with and without Hallucination Proneness. The Spanish Journal of Psychology, 17, E20. doi: dx.doi.org/10.1017/sjp.2014.23

Perona-Garcelán, S., García-Montes, J. M., Rodríguez-Testal, J. F., et al. (2013). Relationship of absorption, depersonalization, and self-focused attention in subjects with and without hallucination proneness. Cognitive Neuropsychiatry, 18(5), 422-436. doi: 10.1080/13546805.2012.728133

Peters, E., Joseph, S., Day, S., \& Garety, P. (2004). Measuring Delusional Ideation. Schizophrenia Bulletin, 30(4), 1005-1022. doi: 10.1093/oxfordjournals.schbul.a007116

Rossler, W., Riecher-Rossler, A., Angst, J., Murray, R., Gamma, A., Eich, D., et al., (2007). Psychotic experiences in the general population: a twenty-year prospective community study. Schizophrenia Research, 92, 1 14. doi: $10.1016 /$ j.schres.2007.01.002

Scott, J., Chant, D., Andrews, G., \& McGrath, J. (2006). Psychotic-like experiences in the general community: the correlates of CIDI psychosis screen items in an Australian sample. Psychological Medicine, 36(2), 231238. doi: $10.1017 / \mathrm{S} 0033291705006392$

Scott, J., Martin, G., Welham, J., Bor, W., Najman, J., O'Callaghan, M., \& McGrath, J. (2009). Psychopathology during childhood and adolescence predicts delusional-like experiences in adults: a 21 -year birth cohort study. The American Journal of Psychiatry, 166(5), 567-574. doi: 10.1176/appi.ajp.2008.08081182

Scott J, Welham J, Martin G, Bor, W., Najman, J., O'Callaghan, M., \& McGrath, Jl. (2008). Demographic correlates of psychotic-like experiences in young Australian adults. Acta Psychiatrica Scandinavica, 118, 230237. doi: $10.1111 /$ j.1600-0447.2008.01214.x

Segal, Z. V., Williams, J. M. G., \& Teasdale, J. D. (2002). Mindfulness-based cognitive therapy for Depression. New York: Guilford Press.

Serper, M., Dill, C. A., Chang, N., Kot, T., \& Elliot, J. (2005). Factorial structure of the hallucinatory experience: continuity of experience in psychotic and normal individuals. Journal of Nervous and Mental Disease, 193(4), 265-272. doi: 10.1097/01.nmd.0000158374.54513.a0

Simón, V. (2007). Mindfulness y neurobiología [Mindfulness y neurobiology]. Revista de Psicoterapia, 66(67), 5-30.

Smeets, F., Lataster, T., Hommes, J., Lieb, R., Wittchen, H. U., \& van Os, J. (2012). Evidence that onset of psychosis in the population reflects early hallucinatory experiences that through environmental risks and affective dysregulation become complicated by delusions. Schizophrenia Bulletin, 38(3), 531-542. doi: 10.1093/schbul/sbq117

So, S. H. W., \& Kwok, N. T. K. (2015). Jumping to conclusions style along the continuum of delusions: Delusion-prone individuals are not hastier in decision making than healthy individuals. PloS ONE, 10(3), e0121347. doi: 10.1371 /journal.pone. 0121347

Soler, J., Tejedor, R., Feliu-Sol, A., Pascual, J. C., Cebolla, A., Soriano, J., \& Pérez, V. (2012). Propiedades psicométricas de la versión española de la escala Mindful Attention Awareness Scale (MAAS). Actas Españolas de Psiquiatría, 40(1), 19-26. 
Stanghellini, G., Langer, A. I., \& Cangas, A. J. (2012). Quality of hallucinatory experiences: differences between a clinical and a non-clinical sample. World Psychiatry, 11(2), 110-113. doi: 10.1016/j.wpsyc.2012.05.007

Van Os, J., Linscott, R. J., Myin-Germeys, I., Delespaul, P., \& Krabbendam, L. (2009). A systematic review and meta-analysis of the psychosis continuum: evidence for a psychosis proneness-persistenceimpairment model of psychotic disorder. Psychological Medicine, 39(2), 179-195. doi: 10.1017/S0033291708003814

Verdoux, H., \& van Os, J. (2002). Psychotic symptoms in non-clinical populations and the continuum of psychosis. Schizophrenia Research, 54(1), 59-65. doi: 10.1016/S0920-9964(01)00352-8
Verdoux, H., Van Os, J., Maurice-Tison, S., Gay, B., Salamon, R., \& Bourgeois, M. (1998). Is early adulthood a critical developmental stage for psychosis proneness? A survey of delusional ideation in normal subjects. Schizophrenia Research, 29, 247-254. doi: 10.1016/S09209964(97)00095-9

Wiles, N. J., Zammit, S., Bebbington, P., Singleton, N., Meltzer, H. \& Lewis, G. (2006). Self-reported psychotic symptoms in the general population. British Journal of Psychiatry, 188, 519-526. doi: 10.1192/bjp.bp.105.012179

(Article received: 30-03-2017; revised: 20-06-2017; accepted: 04-09-2017) 